\title{
Hazardous Household Substances: Alternatives That Are Relatively Free of Toxic Effects ${ }^{1}$
}

\author{
Marie Hammer, Chris Koehler, and Randall Cantrell ${ }^{2}$
}

Some products that we use in our homes contain chemicals that are hazardous or toxic. Hazardous products can be found on our kitchen, bathroom, and garage shelves. In most cases, the concentrations of the chemical products found in the home are much lower than the concentrations of those found in the workplace or commercial settings.

Misuse or improper disposal of hazardous products can pose a threat to your health. Long-term or cumulative problems also can occur, such as contamination of septic tanks, drain fields, and surface and groundwater.

The Federal Hazardous Substances Act (FHSA) requires hazardous household products ("hazardous substances") to bear labeling that alerts consumers to the potential hazards those products present and informs consumers what they need to do to protect themselves and their children. Any products that are used or stored in a home, garage, shed, or other building that is part of the household are covered by the Act.
We can reduce the potential for exposure to chemicals from household products and produce less hazardous household waste by using alternatives that are relatively free of toxic effects.

\section{Why do we use potentially hazardous products?}

Time and convenience are the primary reasons for using potentially hazardous products. In the past, sinks were scrubbed with baking soda, but extra effort was needed to maintain a stain-free sink. So, hazardous products increasingly were used to reduce this extra time and effort. Similarly, wood floors used to be cleaned typically with oil and vinegar or mineral oil-a process that eliminated the need for wax but required more work.

1. This document is FCS3149, one of a series of the Department of Family, Youth and Community Sciences, UF/IFAS Extension. Original publication date June 1988. Revised July 2002 and December 2016. Visit the EDIS website at http://edis.ifas.ufl.edu.

2. Written by Marie Hammer, former professor, Department of Family, Youth and Community Sciences. Revised in 2016 by Chris Koehler, associate professor, Washington State University Extension Grays Harbor County, Elma, Washington; and Randall Cantrell, assistant professor, Department of Family, Youth and Community Sciences; UF/IFAS Extension, Gainesville, FL 32611. Reviewed by Sonja Koukel, community \& environmental health specialist, College of Agriculture, Consumer \& Environmental Sciences, Extension Family \& Consumer Sciences, New Mexico State University; and Gina Peek, associate professor and cooperative Extension housing and consumer specialist, Oklahoma State University.

The use of trade names in this publication is solely for the purpose of providing specific information. UF/IFAS does not guarantee or warranty the products named, and references to them in this publication does not signify our approval to the exclusion of other products of suitable composition. The Cooperative Extension Service assumes no responsibility and disclaims any liability for any injury or damage resulting from the use or effect of any product or information appearing in this document

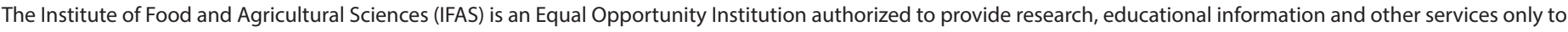

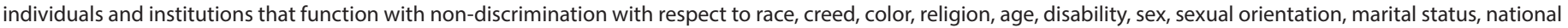
origin, political opinions or affiliations. For more information on obtaining other UF/IFAS Extension publications, contact your county's UF/IFAS Extension office. 


\section{How do I know if a product is}

\section{hazardous?}

Check the label. Many household products used for household cleaning, car care, or yard care can be toxic, corrosive, flammable, or reactive. All of these designations are considered hazardous. The signal words on the label are "CAUTION," "WARNING," or "DANGER." "CAUTION" indicates a lower level of toxicity, and "DANGER" is the highest level of toxicity.

\section{What makes a product hazardous?}

Many common household cleaning products contain dangerous ingredients such as caustics or solvents. When used, stored, or disposed of improperly, these products could threaten your family's health or damage the environment.

\section{Caustics}

Caustic chemicals such as those found in oven cleaners, drain cleaners, and scouring powders can cause burns and severe damage to the skin and eyes. They also can disrupt the $\mathrm{pH}$ balance of septic systems, which is important for them to function properly.

\section{Solvents}

Solvents are fast-drying substances that dissolve another substance (e.g., paint thinners, terpentine, kerosene). Inhalation of these vapors or accidental drinking can be harmful or even fatal. Long-term exposure to some solvents may cause liver and kidney problems, birth defects, centralnervous system disorders, and cancer. Some formulations of furniture polish, silver cleaner, paint remover, and wood floor wax contain solvents.

\section{Use, Storage, and Waste Disposal of Hazardous Products}

Beware of the hazards indicated on the label before using the product. Carefully follow directions concerning use, storage, and disposal. In many cases there will be no specific directions for disposal of the left-over product. The best disposal plan for hazardous products is to use them up according to the directions, or share with a friend. Check your local or county solid waste disposal procedures and options for proper disposal. Different Florida counties will have their own policies about which solid waste materials are accepted at disposal sites. Solid waste centers also might designate additional days when non-acceptable materials can be brought in for disposal.

\section{Reducing the Need for Cleaning}

- Good housekeeping practices will reduce the amount of cleaning products and hazardous household products needed in the home. For example, roaches and other insects are discouraged by good housekeeping practices.

- Store food in sealed containers.

- Wipe up spills immediately.

- Use doormats at all outside entrances to your home.

- Sweep or vacuum your floors often, especially floors that can become scratched or dulled by dirt and grit.

- Clean carpets on a sunny day with the windows open to hasten drying. Do not soak the carpet-it may mildew. In hot, humid climates be mindful of the relative humidity inside a home when opening windows; it should never exceed $50-60 \%$ due to the risks of mold growth.

- Avoid hard-to-clean baked-on stains in the oven by wiping them up after each use and/or use liners to catch spills. Wipe away charred spills with a non-metallic bristle brush.

- Use screens in the kitchen sink, bathroom sink, and tub to prevent items such as food particles or hair from entering the drain pipe.

- Air out the house occasionally to avoid the use of chemical air fresheners.

- Open the window, use an exhaust fan, or both (see note about relative humidity above).

- Use the air conditioner to remove humidity and reduce odors.

- Bathe pets frequently to eliminate fleas and odors.

- Store pet food in sealed containers.

\section{Alternative Cleaning Products}

Today, there are alternative cleaning products and methods that are effective and relatively free of toxic effects. You can reduce handling, use, and disposal of hazards associated with household products by substituting safer alternatives. For example, full-strength vinegar or lemon juice applied to rust stains or hard-water deposits will fade and perhaps eliminate the stain. In some cases, these options may require more effort to get the desired results. Reducing the amount of hazardous products you purchase not only saves money, but also eliminates the threat of accidental personal exposure and/or pollution of the environment. Once you understand the basic substitutes, formulas, and procedures, you can make your own decisions about tradeoffs. 
Fortunately, most households have the basic ingredients on hand for making safer substitutes.

To help you get started, the following alternatives are provided. These products are relatively free of toxic effects.

Test any cleaner first on an inconspicuous area to check for possible discoloration.

Table 1. Where to purchase products mentioned in this publication.

\begin{tabular}{|l|l|}
\hline Cleaning product & Where to purchase \\
\hline Ammonia & Retail or Supermarket \\
\hline $\begin{array}{l}\text { Baking Soda (sodium } \\
\text { bicarbonate) }\end{array}$ & Retail or Supermarket \\
\hline Borax & $\begin{array}{l}\text { Retail, Supermarket, Hardware } \\
\text { store }\end{array}$ \\
\hline Cream of tartar & Supermarket \\
\hline Salt (sodium chloride) & Retail, Supermarket \\
\hline Soap Flakes & Retail, Supermarket, online \\
\hline Vinegar & Retail, Supermarket \\
\hline $\begin{array}{l}\text { Washing Soda (sodium } \\
\text { carbonate) }\end{array}$ & Retail, Supermarket \\
\hline Whiting Powder & Paint Store, Hardware Store \\
\hline
\end{tabular}

\section{Air Fresheners}

- Sprinkle baking soda or place a container of clay-based kitty litter in odor-producing areas.

- Place an open box of baking soda in the refrigerator to absorb food odors.

\section{Aluminum Cleaners}

- Scour corroded aluminum containers with whiting powder (calcium carbonate) and soap jelly (recipe given in General Purpose Cleaners section). Use very fine steel wool to scrub.

- Brighten a discolored aluminum pan by boiling it in one of the following solutions until the discoloration disappears:

- 1 tablespoon vinegar to 1 quart water

- 2 teaspoons cream of tartar to 1 quart water

\section{Bathroom Cleaners/Disinfectants}

- Mildew and other stains can be removed from grout with a solution of $1 / 2$ cup laundry bleach to 1 gallon of water. Apply to grout. Let stand 5 minutes and rinse with clear water. Air dry. (Check manufacturer's label to ensure bleach concentration is safe because bleach concentrations vary.)

\section{FOR SINKS, TUBS, AND VANITIES}

- Wipe fixtures with a damp cloth sprinkled with borax (sodium borate) and rinse.

- Wipe fixtures with a damp cloth sprinkled with washing soda (sodium carbonate) and rinse.

\section{FOR TOILET BOWLS}

- Pour $1 / 2$ cup liquid chlorine bleach into the toilet bowl. Let stand for at least 30 minutes. Scrub with a longhandled brush and flush. Remember, never mix bleach with other household chemicals, such as toilet bowl cleaners, rust removers, acids, or products containing ammonia, because it can create and release a toxic gas.

\section{Brass and Copper Cleaners}

- Combine 1 cup whiting powder, 1 teaspoon ammonia, and 1 pint soap jelly (see General Purpose Cleaners). Mix well. This will make a paste. Apply the paste with a clean cloth and rub into the metal. After using the paste, wash articles in hot sudsy water, rinse, and dry.

- Tarnished copper can be cleaned by sprinkling salt on the surface, applying white vinegar or lemon juice, and lightly rubbing with a soft cloth. Rinse and dry.

- Brass with an antique finish can be polished with lemon oil.

\section{Ceramic Tile Cleaner}

- You may find that clean water, applied with a soft cloth and then dried, will work well. For textured tile, a nylon brush may be needed.

- For periodic, stronger cleaning, add $1 / 2$ cup vinegar to 1 gallon of water. Apply with a soft, wrung-out cloth. Rinse with clean water applied with a soft cloth. Change cleaning solution often.

- If grout is not sealed and becomes dingy, make a paste of baking soda and water. Apply to grout with a nylon bristle brush (or a used toothbrush). Rinse with clean water and a cloth; dry.

\section{Drain Cleaners To Keep Drains Clean}

- Flush pipes using 1/2 cup washing soda dissolved in 2 cups boiling water. Rinse with clean water. Do this once a month.

\section{To Unclog Drains}

- Use a plunger. 
- Mix together 1 cup each of baking soda, salt, and white vinegar. Pour in drain. Wait 15 minutes, then flush thoroughly with boiling water.

- Use a rubber plumber's snake if drain is seriously clogged. (Take precaution not to exert too much force where there are bends in the plastic (PVC) pipe when using a rubber plumber's snake.)

\section{General Purpose Cleaners}

- Add 1/2 cup distilled white vinegar to 1 gallon water.

- Sprinkle baking soda on a damp cloth (as you would for scouring), rinse with water, and polish to shine. For heavier grime, make a paste of baking soda and water, scrub with a cloth, rinse with warm water and wipe dry.

- Use $1 / 2$ lemon dipped in baking soda. Rinse with water, and polish to shine.

- Combine 2 tablespoons ammonia and 2 tablespoons liquid detergent to 1 quart warm water. Wash with a cloth, rinse with warm water, and air dry.

- Soap jelly (used in other formulas). To make, dissolve 1 cup shaved soap (without additives like deodorant or aloe) or soap flakes (such as Castile) in 1 quart boiling water. When entirely melted or dissolved, pour liquid into a wide-mouth jar. Let stand in a cool place until it jells. Store covered. Make as needed.

- Most soap pads are acceptable; for example, scouring pads such as Scotch Brite or SOS pads. Be certain to look for any possible signs of scratching before continuing use with the product.

\section{Oven Cleaners}

- For non-self-cleaning ovens: To remove baked-on grease and spills, scrub with a paste of 1 cup baking soda, 1 cup salt, and 1 cup water. Or sprinkle with dry baking soda, then scrub with a damp cloth. Do not let baking soda touch wires or heating elements. Clean racks and burner inserts with baking soda paste and a scouring pad that will not scratch chrome/steel.

\section{Painted Surfaces}

Method for washing walls: To prevent streaking, wash walls by starting at the baseboard and working upward. If soiled water runs down on the clean surface, clean it up immediately. Gloss-enamel-painted walls are easier to clean than flat-painted walls because they will withstand stronger washing solutions. Dust all painted surfaces thoroughly before washing. (Refer to Resources section for more information.)
- For general cleaning, use soap jelly (see General Purpose Cleaners) or liquid detergent and warm water. Add enough water to the liquid detergent in order to make light suds. Wash with a soft, moist, wrung-out cloth that has been dipped in the cleaning solution. Rinse well with clean water. Dry with a soft, clean cloth. Wash only a small area at a time.

- Whiting paste will remove fingerprints and clean heavily soiled places: mix 4 parts whiting powder with 1 part soap jelly. Store in a 1-quart jar covered with a lid at room temperature. Apply with a soft clean cloth. Rub lightly. Rinse with clean water, and allow to air dry.

\section{Upholstery Cleaner}

- Mix 1/2 cup mild liquid dishwashing detergent with 1 pint boiling water. Let cool. Whip into a thick foam using an electric mixer. Pre-test a small area before proceeding. Apply the foam to the fabric with a damp sponge. Remove the suds with a clean cloth. To rinse, use 1 cup white vinegar added to 1 gallon of lukewarm water. Using a clean white cloth and as little liquid as possible, apply pressure to the area-do not rub. Change the water as needed.

\section{CARPETS AND RUGS}

- Apply the foam in $4 \mathrm{x} 4$ foot sections. Continue the same process as for upholstery.

\section{Windows and Mirrors}

\section{METHODS FOR CLEANING WINDOWS AND MIRRORS}

- Remove surface soil with a damp paper towel or soft cloth. Apply cleaning liquid with a cloth. Squeegee or rub dry and polish with lint-free paper (newspaper works well), microfiber cloth, or chamois.

- Consumer Reports offers home window cleaning tips with this video.

- On windows, rub the inside in one direction and the outside in another to determine which side has streaks. Avoid spilling the cleaner on painted or varnished woodwork because it can damage the finish.

\section{WINDOW CLEANERS}

- Add 2 tablespoons of vinegar to 1 quart water. Because vinegar is a mild acid, it will remove rust or lime deposits on the outside of windows.

- Add 2 tablespoons of ammonia to 1 quart of water. Ammonia is a mild base and cuts grease. 


\section{General Rules for Managing Toxic Household Products}

- Select the least toxic products for your home.

- Buy only as much as you will use to avoid storing and potential health hazards.

- Read the label and follow safety guidelines. The label provides a list of ingredients, instructions for use, and hazards associated with improper use, safe storage, and recommended disposal.

- Dispose of toxic waste as recommended. Never flush toxic waste or medications down drains or toilets. Contact your County Department of Environmental Services for specific information about Amnesty Days and other disposal options.

\section{Safety Considerations if Toxic Products Are Used in the Home}

- Never mix bleach with other household chemicals, such as toilet bowl cleaners, rust removers, acids, or products containing ammonia, because it can create and release a toxic gas.

- Store all cleaning solutions out of reach of children.

- Never transfer a product to a container that once held food or drink.

- Mix cleaning solutions in a well-ventilated area.

- Clean up after using toxic substances by following manufacturer's recommendations.

- Never smoke or eat when handling hazardous materials.

- Keep the container closed. Harmful fumes may escape from an open container.

\section{Resources}

For more information about hazardous household substances see:

The Chemical Information Technology Center (ChemITC ${ }^{\circledR}$ ) of the American Chemistry Council. Accessed on November 10, 2016 from https://chemitc.americanchemistry.com/

American Chemistry Council. Accessed on November 10, 2016 from https://www.americanchemistry.com/default. aspx - press releases and fact sheets on various chemicals, etc.

Consumer Reports. Accessed on November 8, 2016 from http://www.consumerreports.org/home-windows/ window-cleaning-tips/
Consumer Specialties Manufacturers Association, 1667 K Street NW, Suite 300, Washington, DC 20006 (202) 872-8110. A trade association involved with the manufacture, formulation, distribution, and sale of consumer products that help household and institutional customers create cleaner and healthier environments. Accessed on November 10, 2016 from http://www.cspa.org/

The California Environmental Protection Agency, Department of Toxic Substances Control (DTSC) I. Accessed on November 10, 2016 from http://ccelearn.csus.edu/ wasteclass/resources/resources_03.html

Department of Health. Accessed on November 8, 2016 from http://www.doh.wa.gov/YouandYourFamily/HealthyHome/ Contaminants/BleachMixingDangers

Federal Hazardous Substances Act (FHSA). Accessed on November 8, 2016 from https://www.cpsc.gov/Business-Manufacturing/Business-Education/Business-Guidance/ FHSA-Requirements

Florida Department of Environmental Protection, "Regulatory Programs." Accessed on November 10, 2016 from http://www.dep.state.fl.us/secretary/regulatory/default.htm

Florida Department of Environmental Protection, "Green Cleaning - Cleaning to protect health without harming the environment including recipes." Accessed on November 10, 2016 from http://www.dep.state.fl.us/green/cleaning.htm

Florida Department of Environmental Protection. "Household Hazardous Waste." Accessed on November 10, 2016 from http://www.dep.state.fl.us/waste/categories/ hazardous/pages/household.

Florida Department of Environmental Protection. "Hazardous Waste Publications for Distribution." This page contains all of their documents related to the Permitting and Compliance Assistance Program. Accessed on November 10, 2016 from http://www.dep.state.fl.us/waste/categories/ hazardous/pages/publications.htm

"Help Yourself to a Healthy Home." Learn to identify safety risks and hidden dangers in the home environment. Each of the nine chapters includes action steps to help you find problems and suggestions for ways to correct them. Accessed on November 10, 2016 from http://extensionhealthyhomes.org/help.html

"Household Waste Chart" from the Water Environment Federation, 601 Wyeth Street, Alexandria, VA 22314-1994 
(1-800-666-0206). A colorful, easy-to-read chart that establishes the most effective means of disposing of household waste and other fact sheets for the public and resources for elementary and college students. Accessed on November 10, 2016 from http://www.wef.org/PublicInformation/page. aspx?id $=90$

HGTV. Accessed on November 11, 2016 from http:// www.hgtv.com/design/decorating/clean-and-organize/ how-to-clean-walls-and-wallpaper

Poison Help. Accessed on November 29, 2016 fromhttp:// poisonhelp.hrsa.gov/the-poison-help-line/index.html

For more information, contact the Department of Environmental Regulation, County Health Department, or the County Cooperative Extension Office. Your Extension office can provide you with a variety of printed materials on managing household hazardous substances.

The University of Florida Cooperative Extension Service assumes no responsibility and disclaims any liability for any injury or damage resulting from use or effect of any product or information appearing in this section. No endorsements are intended or implied. 